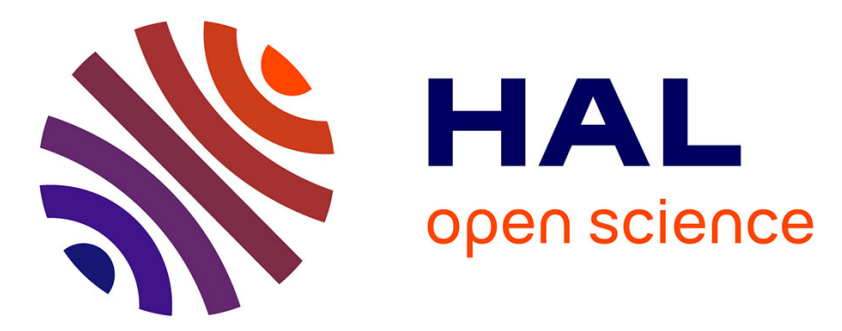

\title{
Coupled abiotic and biotic sulfurization processes during microbial sulfate reduction with alkyl substrates
}

Vincent Grossi, Ingrid Antheaume, Cristiana Cravo-Laureau

\section{To cite this version:}

Vincent Grossi, Ingrid Antheaume, Cristiana Cravo-Laureau. Coupled abiotic and biotic sulfurization processes during microbial sulfate reduction with alkyl substrates. Sulfur Risk Management in Exploration-Production (SRM 2018, EAGE-IFPEN), Sep 2018, Rueil-Malmaison, France. hal02340714

\section{HAL Id: hal-02340714 \\ https://hal.science/hal-02340714}

Submitted on 12 Nov 2019

HAL is a multi-disciplinary open access archive for the deposit and dissemination of scientific research documents, whether they are published or not. The documents may come from teaching and research institutions in France or abroad, or from public or private research centers.
L'archive ouverte pluridisciplinaire $\mathbf{H A L}$, est destinée au dépôt et à la diffusion de documents scientifiques de niveau recherche, publiés ou non, émanant des établissements d'enseignement et de recherche français ou étrangers, des laboratoires publics ou privés. 


\title{
Coupled abiotic and biotic sulfurization processes during microbial sulfate reduction with alkyl substrates
}

\author{
Vincent Grossi $^{1}$, Ingrid Anteaume ${ }^{1}$, Cristiana Cravo-Laureau ${ }^{2}$ \\ ${ }^{1}$ Laboratoire de Géologie de Lyon, CNRS, Université de Lyon, UCBL, ENSL, Villeurbanne, France \\ ${ }^{2}$ Equipe Environnement et Microbiologie, Institut des Sciences Analytiques et de Physico-Chimie \\ pour l'Environnement et les Matériaux, Université de Pau et des Pays de l'Adour, Pau, France
}

\section{Introduction}

The reaction of reduced inorganic sulfur with organic matter $(\mathrm{OM})$ is known to play a crucial role in $\mathrm{C}$ and $\mathrm{S}$ biogeochemical cycles in anoxic environments and in the associated petroleum generation. Depending on the conditions and the types of reagents involved, the abiotic sulfurization of organic compounds can induce the formation of a large array of individual and macromolecular organosulfur compounds (OSC; Sinninghe Damsté and De Leeuw 1990; Amrani 2014), or the reduction of functionalized biomolecules into their corresponding biomarker hydrocarbons (Hebting et al. 2006). In both cases, the sulfurization of organic compounds is considered to enhance OM preservation and potentially lead to the formation of oil source rocks, since OSC and saturated hydrocarbons are generally more resistant to diagenesis than the original biomolecules.

In addition to diagenetic processes, some OSC can also be biosynthesized by living cells, where sulfur plays a key role in biochemical functioning and OSC mostly occur as amino acids and proteins. The microbial transformation of OSC has also been reported but, so far, such reactions have been limited to aerobic bacteria grown on commercially available OSC substrates (Uthoff et al. 2005), and to in vitro synthesis using enzyme-catalyzed reactions (Weber et al. 2004).

The geochemical impact of microbial processes involved in S-cycle [such as microbial sulfate-reduction (MSR)] in sediments and petroleum reservoirs has been thoroughly investigated, but most studies have focused on S-isotope fractionation (Canfield 2001), or on the degradation potential of the microbial communities (Aitken et al. 2013). These approaches seem to have set aside the possible coupling between abiotic and biotic processes likely to occur during the degradation of OM under S-reducing conditions, and possibly influencing the type of OSC formed, as well as the fate and the diagenetic stability of OSC. Here, we investigated such a coupling in anaerobic cultures of heterotrophic sulfatereducing bacteria (SRB) grown under laboratory conditions on different types of $n$-alkyl substrates.

\section{Material and Methods}

Cultures of four mesophilic strains of hydrocarbon-degrading SRB belonging to the class Deltaproteobacteria and isolated from oil-polluted sediments were grown in synthetic sulfate-reducing medium with different types of substrate (octanoate, saturated and unsaturated hydrocarbons, alkanol or alkanethiol) as sole source of carbon and energy (Table 1). All cultures were incubated under optimal anaerobic growth conditions $\left(\sim \mathrm{pH} 7,30^{\circ} \mathrm{C}\right)$. Cells were harvested after different incubation times (up to 3 weeks) by filtration on glass microfiber filters.

Part of the filtered cells were ultrasonically extracted using a solvent mixture and the total lipid extracts (TLE) thus obtained were chromatographed over a packed column of silica gel. This allowed the residual substrate to be separated from neutral and more polar intracellular and membrane lipids which were analyzed by gas chromatography-mass spectrometry (GC-MS) following an eventual hydrolysis step. 


\section{SRM2018}

\section{Results and Discussion}

The neutral lipid fraction of two out of the four strains of SRB grown on unsaturated hydrocarbons ( $n$ alk-1-enes), showed the presence of series of long-chains wax esters (WE) and thiowax esters (TWE) (Table 1), whose distributions depended on the substrate used for growth. These compounds were identified based on their mass spectral characteristics and comparison with synthetic standard. WE biosynthesis by aerobic (hydrocarbon-degrading) bacteria has been known for long and intensively investigated. The report of the natural biosynthesis of WE and TWE in anaerobic (sulfate-reducing) bacteria is however unprecedented. It is noteworthy that WE and TWE were not produced during growth of the SRB on octanoate (Table 1), even under N-starved conditions supposed to favor the intracellular accumulation of WE (Uthoff et al. 2005).

Table 1 Sulfate-reducing bacteria used for the coupling of abiotic and biotic sulfurization processes.

\begin{tabular}{ccccc}
\hline Strain & Growth substrate & $\begin{array}{c}\text { Wax ester } \\
\text { production }\end{array}$ & $\begin{array}{c}\text { Thio wax ester } \\
\text { production }\end{array}$ & $\begin{array}{c}\text { Disulfide dimer } \\
\text { production }\end{array}$ \\
\hline \multirow{3}{*}{ Strain $A$} & $\mathrm{C}_{14}-\mathrm{C}_{17} n$-alk-1-enes & Yes & Yes & Yes \\
& $\mathrm{C}_{16}$ alkan-1-ol & Yes & Yes & No \\
& $\mathrm{C}_{16}$ alkan-1-thiol & Yes & Yes & Yes \\
& Octanoate & No & No & No \\
\hline Strain $B$ & $\mathrm{C}_{16} n$-alk-1-ene, & Yes & Yes & Yes \\
& Octanoate & No & No & No \\
\hline Strain $C$ & $\mathrm{C}_{15}-\mathrm{C}_{16} n$-alk-1-enes & No & No & Yes \\
\hline Strain $D$ & $\mathrm{C}_{15}-\mathrm{C}_{16} n$-alk-1-enes & No & No & Yes \\
\hline
\end{tabular}

Surprisingly, unlike WE, the length of the alkyl chain of all TWE formed from a given $n$-alkene substrate was systematically the same than that of the substrate, whereas the acyl counterparts of TWE showed variable chain lengths similar to that of cellular fatty acids (Fig. 1). This suggested that part of the substrate, or of an activated derivative, was sulfurized during incubation, yielding a sulfurized intermediate that was condensed with different fatty acids to form TWE (Fig. 1). The additional detection of dialkyl disulfides (Table 1) formed by dimerization of the alkene substrates attested for abiotic sulfurization reactions occurring during culture incubation. This is noteworthy given the generally low reactivity of isolated double bonds toward direct sulfurization under aquatic conditions (Amrani 2014).

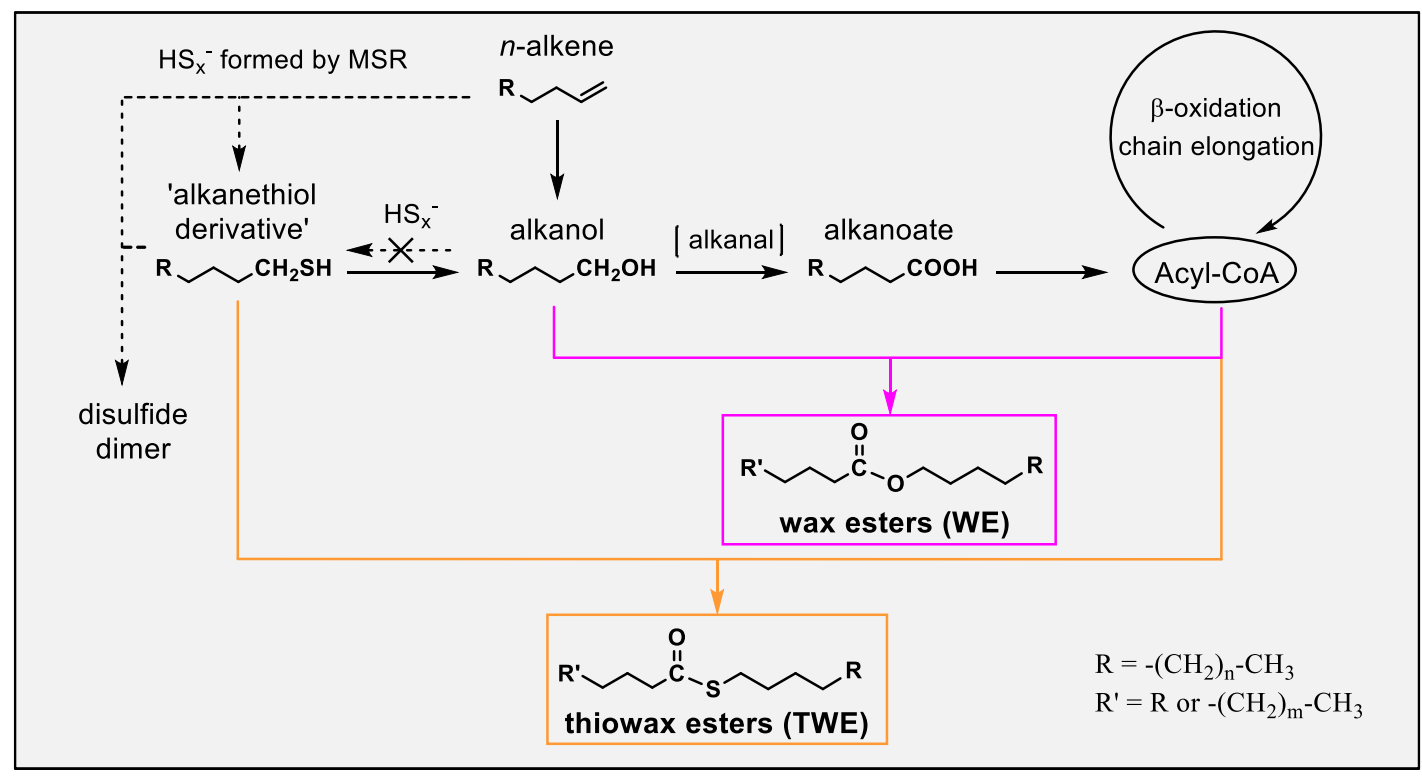


Figure 1 Proposed pathways for the coupled abiotic and biotic formation of sulfurized microbial lipids during growth of SRB on n-alkyl substrates. Dashed lines indicate abiotic reactions; solid lines indicate biotic reactions.

Alkanethiols were not detected in any lipid extract obtained during growth on $n$-alkenes suggesting that such OSC either were not the sulfurized intermediates involved in TWE biosynthesis, or were immediately trapped into TWE following their formation. This latter hypothesis was shown plausible when an alkylthiol was used as a growth substrate for the SRB. Indeed, this type of OSC could be metabolized into cell constituents including series of WE and TWE (Table 1) but, as for $n$-alkene substrates, all TWE exhibited the same alkyl chain than the thiol used for growth (Figs. 1 and 2).

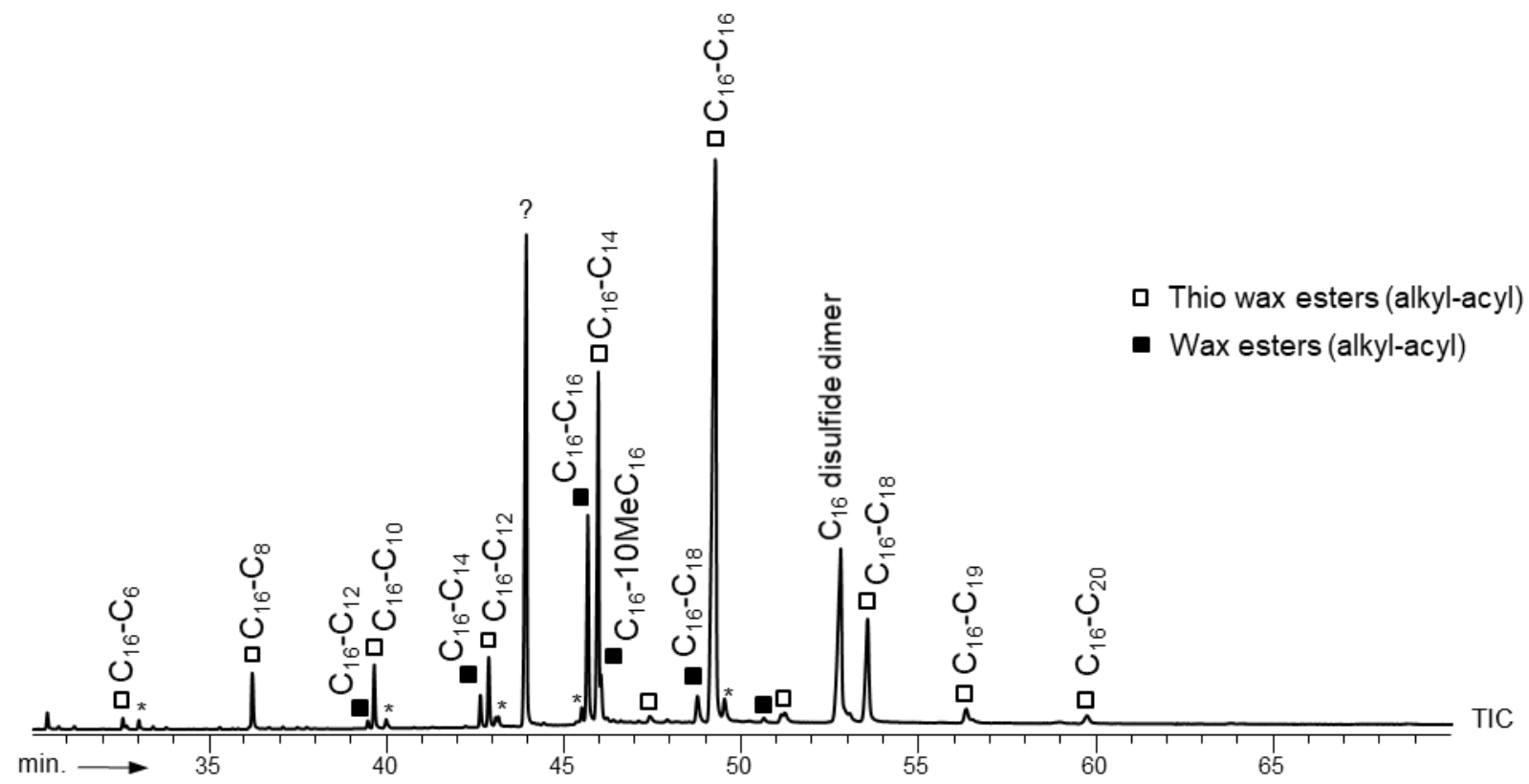

Figure 2 GC-MS trace of the wax esters (WE) and thio wax esters (TWE) formed during growth of SRB on $C_{16}$ alkan-1-thiol. ? = unidentified.

The possibility that an oxidized form of $n$-alkenes has constituted the organic substrate for inorganic sulfur addition during the aforementioned incubations with $n$-alkenes was also tested by growing SRB cells on $n$-alkanol. Alcohols and fatty acids are poorly prone to abiotic sulfurization but their oxidation intermediates, i.e. aldehydes, are considered important organic substrates for sulfurization in the environment (Amrani 2014). When grown on $n$-alkanol as sole source of carbon and energy, the SRB strains produced a whole series of WE but no TWE, indicating that none of the aforementioned oxidation forms of $n$-alkene (i.e., $n$-alkanol, $n$-alkanal and $n$-fatty acid), that were produced intracellularly during substrate assimilation (as attested by WE formation), was involved in the biotic production TWE.

Taken together, our results show that in addition to being used as carbon and energy sources by the SRB, part of the $n$-alkyl substrates can be sulfurized (by reaction with biotically-produced sulfides) inducing the formation of a (yet to be identified) S-derivative which then served as sole building block for TWE biosynthesis by condensation with the different cellular fatty acids (Fig. 1).

\section{Conclusions and possible implications}

We here demonstrate that abiotic and biotic sulfurization processes can concomitantly occur during the degradation of OM by MSR, and that sulfurization of OM can lead to the formation of OSC that, in 


\section{SRM2018}

return, can potentially fuels MSR. It can thus be envisaged that, in some circumstances, MSR can 1) counterbalance the apparent recalcitrance of OSC formed abiotically by metabolizing them further into cell biomass and/or other less recalcitrant OSC and, 2) decrease the content in OSC (and thus increase the quality) of the preserved OM/oil. The biogeochemical importance of such processes still needs to be evaluated.

In addition to the enlargement of the panel of interactions that can occur during OM diagenesis in hydrocarbon-containing anoxic sediments and oil reservoirs, our study opens up new perspectives on mechanistic aspects involved in the sulfurization under natural conditions of organic compounds that are supposed not reactive with inorganic sulfur species.

\section{Acknowledgements}

This work was funded by the French National Research Agency/Agence Nationale de la Recherche (grant ANR-12-BSV7-0003 to VG; project BAGEL).

\section{References}

Aitken, C.M., Jones, D.M., Maguire, M.J., Gray, N.D., Sherry, A., et al. [2013] Evidence that crude oil alkane activation proceeds by different mechanisms under sulfate-reducing and methanogenic conditions. Geochimica et Cosmochimica Acta, 109, 162-174.

Amrani, A. [2014] Organo sulfur compounds: Molecular and isotopic evolution from biota to oil and gas. Annual Review of Earth and Planetary Sciences, 42, 733-768.

Canfield, D.E. [2001] Isotope fractionation by natural populations of sulfate-reducing bacteria. Geochimica et Cosmochimica Acta, 65, 1117-1124.

Hebting, Y., Schaeffer, P., Behrens, A., Adam, P., Schmitt, G., et al. [2006] Biomarker evidence for a major preservation pathway of sedimentary organic carbon. Science, 312, 1627-1631.

Sinninghe Damsté, J.S. and de Leeuw, J.W. [1990] Analysis, structure and geochemical significance of organicallybound sulfur in the geosphere: state of the art and future research. Organic Geochemistry, 16, 1077-1101.

Uthoff, S., Stöveken, T., Weber, N., Vosmann, K., Klein, E., et al. [2005] Thio Wax Ester Biosynthesis Utilizing the Unspecific Bifunctional Wax Ester Synthase/Acyl Coenzyme A:Diacylglycerol Acyltransferase of Acinetobacter sp. Strain ADP. Applied and Environmental Microbiology, 71, 790-796.

Weber, N., Klein, E., Vosmann, K. and Mukherjee K.D. [2004] Mono-thioesters and di-thioesters by lipase-catalyzed reactions of $\alpha, \omega$-alkanedithiols with palmitic acid or its methyl ester. Applied Microbiology and Biotechnology, 64, 800-805. 